\title{
Differences between predicted outer membrane proteins of Pasteurella multocida, Histophilus somni, and genotype 1 and 2 Mannheimia haemolytica strains isolated from cattle
}

\author{
Emily L. Wynn and Michael L. Clawson
}

\begin{abstract}
Common bacterial causes of bovine respiratory disease (BRD) include Histophilus somni, Mannheimia haemolytica, and Pasteurella multocida. Within M. haemolytica, two major genotypes are commonly found in cattle (1 and 2); however, genotype 2 strains are isolated from diseased lungs much more frequently than genotype 1 strains. Outer membrane proteins (OMPs) of H. somni, P. multocida, and genotype $2 \mathrm{M}$. haemolytica may be important factors for acquired host immunity. The predicted OMP differences between genotypes 1 and 2 M. haemolytica have been previously identified. In this study, we expanded the focus to include bovine-isolated strain genomes representing all three species and the two M. haemolytica genotypes. Reported here are the core genomes unique to each of them, core genomes shared between some or all combinations of the three species and two M. haemolytica genotypes, and predicted OMPs within these core genomes. The OMPs identified in this study are potential candidates for further studies and the development of interventions against BRD.
\end{abstract}

Key words: Histophilus somni, Mannheimia haemolytica, Pasteurella multocida, outer membrane proteins, bovine respiratory disease.

Résumé : Les bactéries le plus souvent en cause dans les maladies respiratoires des bovins (MRB) incluent Histophilus somni, Mannheimia haemolytica et Pasturella multocida. Au sein du M. haemolytica, deux génotypes majeurs sont communément rencontrés chez les bovins (génotypes 1 et 2), mais les souches du génotype 2 sont isolées de poumons atteints beaucoup plus souvent que les souches du génotype 1. Les protéines de la membrane externe (PME) de H. somni, P. multocida et du génotype 2 de M. haemolytica pourraient constituer des facteurs importants pour l'immunité acquise chez l'hôte. Des différences prédites au niveau des PME entre les génotypes 1 et 2 de $M$. haemolytica ont été identifiées précédemment. Dans ce travail, les auteurs élargissent la portée de ces recherches en étudiant les génomes de souches isolées de bovins pour les trois espèces et les deux génotypes de $M$. haemolytica. Les auteurs rapportent ici les génomes partagés qui sont uniques à chacune d'elles, les portions de ces génomes qui sont communes à toutes ou à certaines combinaisons de ces trois espèces et deux génotypes de M. haemolytica, ainsi que les PME prédites au sein de ces génomes partagés. Les PME identifiés dans ce travail constituent des candidats potentiels pour des études plus approfondies et pour la mise au point de méthodes d'intervention pour contrer les MRB. [Traduit par la Rédaction]

Mots-clés : Histophilus somni, Mannheimia haemolytica, Pasturella multocida, protéines de la membrane externe, maladies respiratoires des bovins.

\section{Introduction}

Bovine respiratory disease $(\mathrm{BRD})$ is a multifactorial disease that affects cattle worldwide, with severe animal health, well-being, and economic ramifications (Rice et al. 2007). BRD can result from combinations of stress, host genetics, and viral and bacterial infections (Taylor et al. 2010). Histophilus somni, Mannheimia haemolytica, and Pasteurella multocida are all members of the Pasteurellaceae family and are common bacterial causes of BRD (Klima et al. 2019; Klima et al. 2020). These gram-negative bacteria are opportunistic pathogens that colonize the nasopharynx of healthy cattle and can invade their lungs and cause BRD during times of general poor health, stress, and viral

Received 23 April 2021. Accepted 27 July 2021.

E.L. Wynn and M.L. Clawson. United States Department of Agriculture, Agricultural Research Service, U.S. Meat Animal Research Center, Clay Center, NE, 68933, USA.

Corresponding author: Michael L. Clawson (email: mike.clawson@usda.gov).

Copyright remains with the author(s) or their institution(s). This work is licensed under a Creative Commons Attribution 4.0 International License (CC BY 4.0), which permits unrestricted use, distribution, and reproduction in any medium, provided the original author(s) and source are credited. 
infections (Amat et al. 2019; Caswell 2014; Dabo et al. 2007; Singh et al. 2011).

Outer membrane proteins (OMPs) belonging to pathogenic members of the Pasteurellaceae family may be important antigens for acquired bovine immunity directed against them (Ackermann and Brogden 2000; Confer and Ayalew 2018). Previously, several differences in the predicted outer membrane proteomes of genotype 1 and genotype $2 \mathrm{M}$. haemolytica have been identified, including a porin, ligand-gated channel, protease $S 6$, and three adhesins that were intact in genotype 2 and not genotype 1 strains (Clawson et al. 2020). The two genotypes were originally identified by whole genome sequencing of 1133 M. haemolytica strains (Clawson et al. 2016). Genotype 1 is represented by commensal-like serotype A2 strains, whereas genotype 2 is represented by more BRD pathogenic serotype A1 and A6 strains (Clawson et al. 2020). Thus, OMPs specific to genotype $2 \mathrm{M}$. haemolytica represent interesting targets for the study of genotype 2 specific pathogenesis and immunogenicity.

Here, we expanded the analyses conducted on genotypes 1 and $2 \mathrm{M}$. haemolytica predicted OMPs. We included additional available whole genomes of M. haemolytica, and those of H. somni and P. multocida that all originated from bovine-isolated strains to identify OMPs of the core genome of each species, as well as the shared core genome of each combination of species. By identifying OMPs that are shared by the core genomes of all combinations of these three species of Pasteurellaceae, it may be possible to identify epitopes that provide a common immune response to all three of them, or epitopes that provide an immune response specific to two or one species, as well as genotypes of M. haemolytica.

\section{Materials and methods}

Whole genomes of M. haemolytica $(n=84), H$. somni $(n=21)$, and P. multocida $(n=29)$ isolated from cattle were downloaded from GenBank on 17 April 2020 (File S1 ${ }^{1}$ ). To ensure consistent annotation, all genomes were annotated using DFAST (v1.2.6) (Tanizawa et al. 2018). To identify homologous coding sequences across species, a pan-genome analysis was performed with EDGAR (v2.3) (Blom et al. 2016) using H. somni genome CP000436.1 as a reference. The pan-genome analysis output was sorted to extract the core genome of each individual species and the core genome shared between species; a 95\% cutoff was applied to be considered core. Amino acid sequences of the core genomes were analyzed by BOMP (Berven et al. 2004) to identify beta-barrel motifs and predict OMPs. Coding sequences that were predicted to be localized to the outer membrane were then analyzed by Boctopus2 (Hayat et al. 2016) to confirm the outer membrane prediction as well as to identify the specific amino acids likely to be found in the extracellular loop (EL) domains of the OMP.
Python scripts were written and used to extract amino acid sequences from the sorted EDGAR output (https://github. com/EmilyWynn/EDGAR-protein-grabber). To measure the similarity of the predicted OMPs across species, alignments were made using a BLOSUM62 scoring matrix for both the full-length proteins and their predicted EL domains.

\section{Ethics approval}

This research project did not involve experimental work with humans or animals.

\section{Results}

A pan-genome of 7577 genes was identified from the 134 genomes of the three Pasteurellaceae species analyzed in this study (File $S 2^{1}$ ). A total of 206 genes were unique to H. somni, 581 were unique to M. haemolytica (found in both genotypes), 143 were unique to genotype $1 \mathrm{M}$. haemolytica, 104 were unique to genotype $2 \mathrm{M}$. haemolytica, and 346 were unique to P. multocida (Fig. 1A; File S2 ${ }^{1}$ ).

Three genes encoding predicted OMPs were identified in the shared core genome of all three species: a TonBdependent receptor protein TBDR, an OMP assembly factor BamA, and an LPS assembly protein LptD (Fig. 1B; Files $\mathrm{S} 3$ and $\mathrm{S}^{1}$ ). The consensus sequence of all LptD protein isoforms was 793 amino acids long, with 224 amino acids predicted to localize to the EL domains (File $S 5^{1}$ ). The full-length LptD protein had a minimum similarity of $83.5 \%$ among all three species, and the predicted EL domains had a minimum similarity of $81.9 \%$ (Table 1; File $\mathrm{S6}^{1}$ ). The consensus sequence of all BamA protein isoforms was 814 amino acids long, with 185 amino acids predicted in the EL domains (File $S 5^{1}$ ). The full-length BamA protein had a minimum similarity of $84 \%$ among all three species, and the predicted EL domains had a minimum similarity of $71.7 \%$ (Table 1 ; File $S 6^{1}$ ). The consensus sequence of all TBDR protein isoforms was 1019 amino acids long, with 481 amino acids predicted in the EL domains. The full-length TBDR protein had a minimum similarity of $63.4 \%$ among all three species, and the predicted EL domains had a minimum similarity of 57.3\% (Table 1; File S6 ${ }^{1}$ ). Another TBDR-encoding gene was shared between $M$. haemolytica and P. multocida strains, in addition to the one observed across all three species (Fig. 1; File $5^{1}{ }^{1}$.

Three genes encoding predicted OMPs were identified in the shared core genome of M. haemolytica and P. multocida, but not in H. somni: an exo-alpha-sialidase, a TonB-dependent receptor protein, and a TPR repeatcontaining protein (Files S3 and S4 ${ }^{1}$ ). The exo-alphasialidase had a consensus sequence of 806 amino acids long, with 7 amino acids predicted in an EL domain (File $\mathrm{S}^{1}{ }^{1}$ ). This EL domain had $100 \%$ similarity between M. haemolytica and P. multocida (Table 1; File S6 ${ }^{1}$ ). The TonBdependent receptor protein had a consensus sequence 811 amino acids long, with 384 amino acids predicted in

\footnotetext{
${ }^{1}$ Supplementary data are available with the article at https://doi.org/10.1139/gen-2021-0038.
} 
Fig. 1. (A) The number of genes in the shared and unique core genomes of Histophilus somni, the two major genotypes of Mannheimia haemolytica, and Pasteurella multocida. Core genome analysis was done by EDGAR. (B) Predicted outer membrane proteins (OMPs) in the shared and unique core genomes of $\mathrm{H}$. somni, the two major genotypes of M. haemolytica, and P. multocida. OMP beta-barrel predictions were analyzed by BOMP and Boctopus2.

A

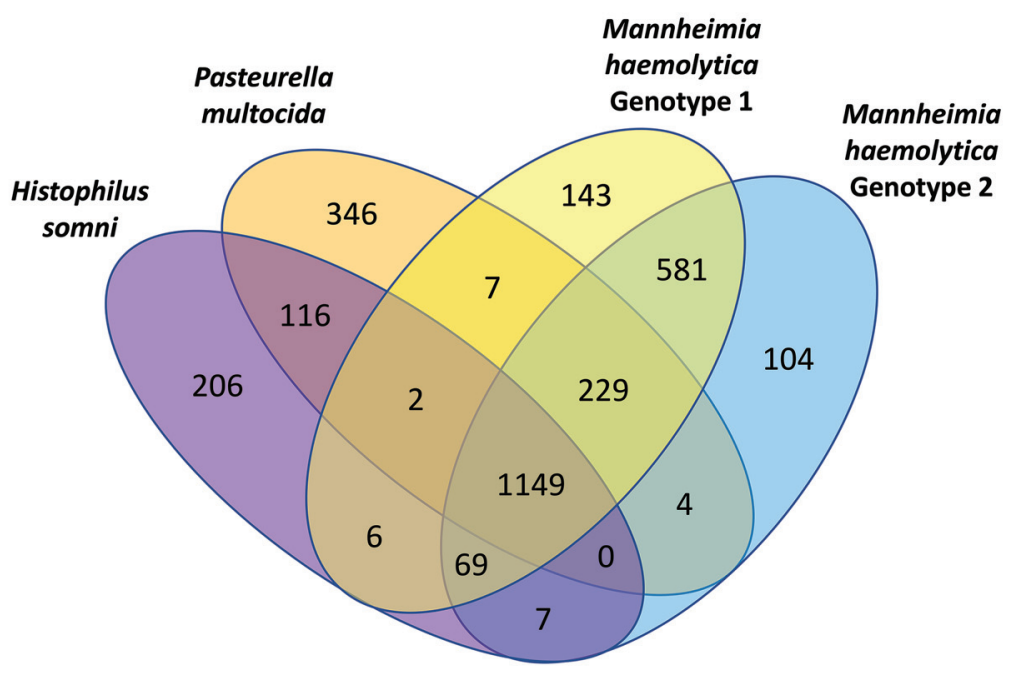

B

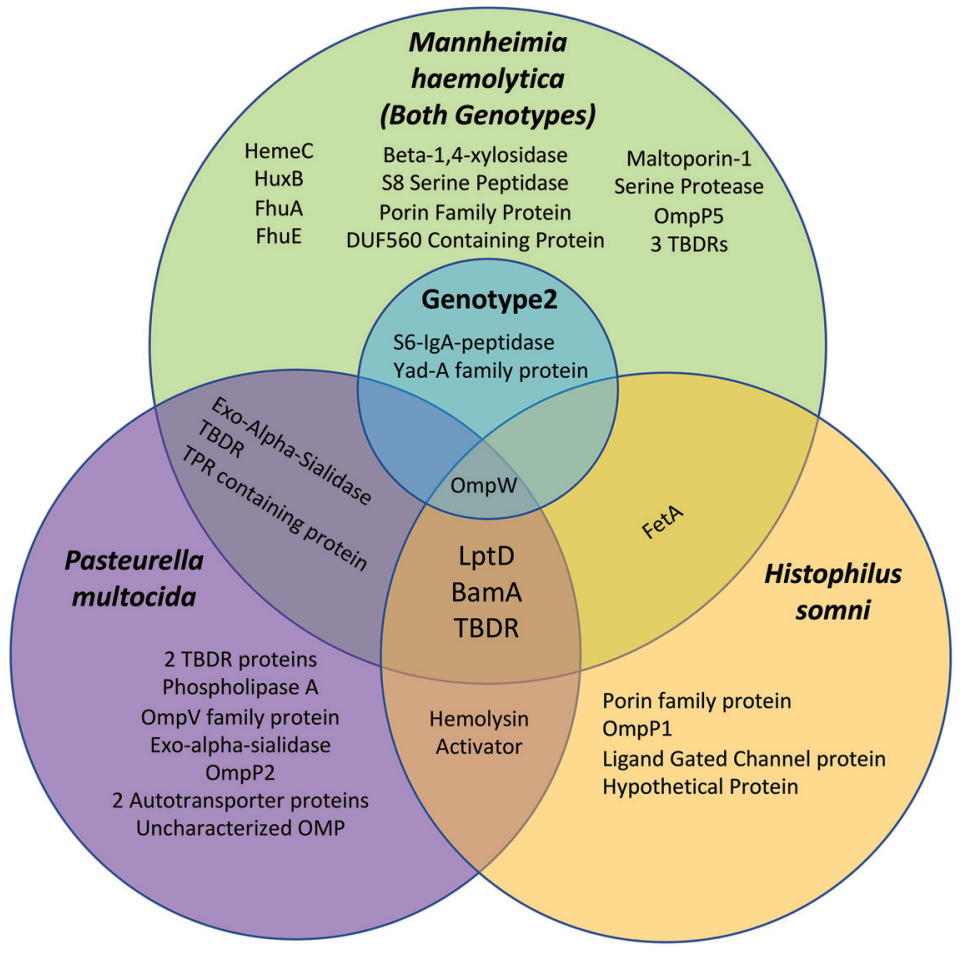

the EL domains (File $S 5^{1}$ ). The TPR repeat-containing protein has a consensus sequence of 605 amino acids long, with 185 amino acids predicted in the EL domains (File S5 ${ }^{1}$ ).

One gene encoding a predicted OMP was identified in the shared core genome of $M$. haemolytica and H. somni, but not in P. multocida, an enterobactin receptor FetA. The consensus sequence of the FetA protein was 709 amino acids long, with 304 amino acids predicted in the EL domains. This FetA protein had a minimum of $83 \%$ overall similarity between M. haemolytica and H. somni, and $70 \%$ similarity in the EL domains (Table 1; File S6 ${ }^{1}$ ).
At the single-species level of specificity, P. multocida strains had nine genes encoding predicted OMPs that were not detected in M. haemolytica and H. somni: a phospholipase A, two autotransporter outer membrane betabarrel domain-containing proteins, an OmpV family protein, an exo-alpha-sialidase, an uncharacterized OMP, an OMP P2, and two TonB-dependent receptor proteins (Files $\mathrm{S} 3$ and $\mathrm{S}^{1}{ }^{1}$ ). Regarding $\mathrm{H}$. somni, four genes encoding predicted OMPs were identified that were not detected in M. haemolytica or P. multocida: a porin family protein, OmpP1, a ligand-gated channel protein, and an uncharacterized 
Table 1. Predicted outer membrane proteins (OMPs) and minimum similarity (BLOSUM62) of full-length protein and extracellular loop regions.

\begin{tabular}{|c|c|c|c|c|c|c|}
\hline Gene & $\begin{array}{l}\text { Histophilus } \\
\text { somni }\end{array}$ & $\begin{array}{l}\text { Mannheimia } \\
\text { haemolytica } \\
\text { genotype } 1\end{array}$ & $\begin{array}{l}\text { Mannheimia } \\
\text { haemolytica } \\
\text { genotype } 2\end{array}$ & $\begin{array}{l}\text { Pasteurella } \\
\text { multocida }\end{array}$ & $\begin{array}{l}\text { Full length } \\
\text { OMP minimum } \\
\text { similarity (\%) }\end{array}$ & $\begin{array}{l}\text { OMP extracellular } \\
\text { loop minimum } \\
\text { similarity (\%) }\end{array}$ \\
\hline Hemolysin activator & $\mathrm{X}$ & & & $\mathrm{X}$ & 85.9 & 80.7 \\
\hline Beta 1,4-xylosidase & & $\mathrm{X}$ & $\mathrm{X}$ & & 100 & 100 \\
\hline DUF560 & & $\mathrm{X}$ & $\mathrm{X}$ & & 82.5 & 89.6 \\
\hline FhuA & & $\mathrm{X}$ & $\mathrm{X}$ & & 99.8 & 89.2 \\
\hline FhuE & & $\mathrm{X}$ & $\mathrm{X}$ & & 99.6 & 98.9 \\
\hline HemeC & & $\mathrm{X}$ & $\mathrm{X}$ & & 93.8 & 79.5 \\
\hline HuxB & & $\mathrm{X}$ & $\mathrm{X}$ & & 99.6 & 98.6 \\
\hline Maltoporin & & $\mathrm{X}$ & $\mathrm{X}$ & & 99.2 & 99.4 \\
\hline OmpP5 & & $\mathrm{X}$ & $\mathrm{X}$ & & 93.3 & 87.8 \\
\hline Porin & & $\mathrm{X}$ & $\mathrm{X}$ & & 100 & 100 \\
\hline S8 serine protease & & $\mathrm{X}$ & $\mathrm{X}$ & & 94.3 & 94 \\
\hline Serine protease & & $\mathrm{X}$ & $\mathrm{X}$ & & 100 & 100 \\
\hline TBDR 1 & & $\mathrm{X}$ & $\mathrm{X}$ & & 99.4 & 99.7 \\
\hline TBDR 2 & & $\mathrm{X}$ & $\mathrm{X}$ & & 98.9 & 99.1 \\
\hline TBDR 3 & & $\mathrm{X}$ & $\mathrm{X}$ & & 100 & 100 \\
\hline S6 IgA peptidase & & & $\mathrm{X}$ & & 61.5 & 81.6 \\
\hline YadA & & & $\mathrm{X}$ & & 72.4 & 100 \\
\hline Exo-alpha-sialidase & & $\mathrm{X}$ & $\mathrm{X}$ & $\mathrm{X}$ & 83.4 & 100 \\
\hline TBDR & & $\mathrm{X}$ & $\mathrm{X}$ & $\mathrm{X}$ & 66.8 & 63 \\
\hline TPR & & $\mathrm{X}$ & $\mathrm{X}$ & $\mathrm{X}$ & 70.6 & 61 \\
\hline OmpW & $\mathrm{X}$ & & $\mathrm{X}$ & $\mathrm{X}$ & 68.4 & 56.6 \\
\hline FetA & $\mathrm{X}$ & $\mathrm{X}$ & $\mathrm{X}$ & & 83 & 70 \\
\hline Hypothetical protein & $\mathrm{X}$ & & & & 81.2 & 67.8 \\
\hline Ligand-gated channel & $\mathrm{X}$ & & & & 94.4 & 86.9 \\
\hline OmpP1 & $\mathrm{X}$ & & & & 99.5 & 97.8 \\
\hline Porin & $\mathrm{X}$ & & & & 93.3 & 94 \\
\hline Autotransporter 1 & & & & $\mathrm{X}$ & 94.5 & 92.7 \\
\hline Autotransporter 2 & & & & $\mathrm{X}$ & 98.8 & 96.4 \\
\hline Exo-alpha-sialidase & & & & $\mathrm{X}$ & 90.6 & 55.9 \\
\hline Outer membrane protein & & & & $\mathrm{X}$ & 76.6 & 59.7 \\
\hline OmpP2 & & & & $\mathrm{X}$ & 68 & 46.4 \\
\hline OmpV & & & & $\mathrm{X}$ & 99.2 & 96.7 \\
\hline Phospholipase A & & & & $\mathrm{X}$ & 100 & 100 \\
\hline TBDR 1 & & & & $\mathrm{X}$ & 99.4 & 98.2 \\
\hline TBDR 2 & & & & $\mathrm{X}$ & 99.3 & 98.1 \\
\hline BamA & $\mathrm{X}$ & $\mathrm{X}$ & $\mathrm{X}$ & $\mathrm{X}$ & 84 & 71.7 \\
\hline LptD & $\mathrm{X}$ & $\mathrm{X}$ & $\mathrm{X}$ & $\mathrm{X}$ & 83.5 & 81.9 \\
\hline TBDR & $\mathrm{X}$ & $\mathrm{X}$ & $\mathrm{X}$ & $\mathrm{X}$ & 63.4 & 57.3 \\
\hline
\end{tabular}

hypothetical protein (Files S3 and S4 ${ }^{1}$ ). For M. haemolytica, 14 genes were identified that were predicted to encode OMPs that were not detected in P. multocida and H. somni: three TonB-dependent receptor proteins, a heme/hemopexin utilization protein $C$, a heme/hemopexin transporter protein HuxB, a ferrichrome porin FhuA, a ferricrhodotorulic acid/ ferriccoprogen receptor FhuE, a Beta-1,4-xylosidase, an S8 serine peptidase, a porin family protein, a DUF560 containing protein, a Maltoporin-1, a serine protease, and OmpP5 (Files S3 and S4 ${ }^{1}$ ). For a full list of these proteins, as well as their minimum similarity within a species, see Table 1.

\section{Discussion}

The bovine nasopharynx supports a diverse microbial community that can include commensal bacteria as well as pathogens (Amat et al. 2019). Identifying OMPs that are specific to particular pathogenic species or that are shared between multiple pathogens is an important step towards developing treatment strategies that can target pathogenic species without disrupting the commensal microbiome. Here, we identified the shared and unique core genomes of $\mathrm{H}$. somni, P. multocida, and both major genotypes of M. haemolytica and identified predicted OMPs that are unique or shared between all combinations of these species.

Previously, a peptidase S6, porin, ligand-gated channel protein, and three trimeric autotransporter adhesins (B, D, and G) were found to be specific to genotype 2 M. haemolytica versus genotype 1 (Clawson et al. 2020). The peptidase S6, ligand-gated channel, and adhesin G 
OMPs identified in that study were annotated as S6-IgApeptidase, HemeC, and YadA family protein, respectively, by DFAST in this study. Both the S6-IgA peptidase and YadA family protein were genotype $2 \mathrm{M}$. haemolytica specific (Fig. 1B).

DFAST annotation of the HemeC gene reported previously as a ligand-gated channel pseudogene in genotype 1 $M$. haemolytica assigned an alternate start codon in genotype 1 strains slightly downstream of the original NCBI annotated start codon. Thus, the gene was not annotated as a pseudogene by DFAST, and further analysis is needed to determine whether a functional protein is expressed. The porin previously described as genotype $2 \mathrm{M}$. haemolytica specific did not meet the $95 \%$ cutoff to be included in the core genome; as noted previously, not all genotype 2 strains carry this gene (Clawson et al. 2020).

Adhesin B of genotype $2 \mathrm{M}$. haemolytica is split into two genes (B1 and B2) in genotype 1 strains (Clawson et al. 2020). In this study, genotype $1 \mathrm{M}$. haemolytica $\mathrm{B} 2$ adhesin was matched to the full-length adhesin $B$ of genotype 2 strains, as the two regions share high homology (Clawson et al. 2020). However, the genotype $1 \mathrm{~B} 2$ adhesin isoform is only $67 \%$ of the amino acid size of the predominant adhesin B isoform of genotype 2 strains. DFAST annotated the genotype $1 \mathrm{M}$. haemolytica version of adhesin $\mathrm{D}$ with an alternate start codon that is downstream of the original start codon and multiple stop codons annotated for the gene by NCBI. However, this genotype $1 \mathrm{M}$. haemolytica version of adhesin D is only $62 \%$ of the amino acid length of the predominant adhesin D isoform of genotype 2 strains. Thus, genotype $1 \mathrm{M}$. haemolytica adhesin B and D isoforms remained markedly different from those of genotype 2 strains in the analyses performed in this study. None of the six OMPs previously found to be specific to genotype $2 \mathrm{M}$. haemolytica were detected in the genomes of $H$. somni or P. multocida.

The bovine lung is an iron-poor environment; thus, the acquisition and utilization of iron is very important. Many siderophores canonically associated with iron uptake in pathogenic bacteria are apparently absent in M. haemolytica (Reissbrodt et al. 1994), but several proteins involved in iron uptake have been identified (Roehrig et al. 2007). Several of the proteins identified in the outer membrane core of the Pasteurellaceae species in this study, such as the TonB-dependent receptors, are likely involved in iron binding and uptake (Kingsley et al.1996; Reissbrodt et al.1994). The pervasiveness and diversity of these proteins, both across and within species, indicates the importance of iron uptake as a limiting factor within the nasopharyngeal niche and makes these proteins potential targets for host immune responses.

LptD is a protein involved in the assembly of lipopolysaccharides (LPS) in the outer membrane. LPS is an endotoxin and a general virulence attribute of gram-negative bacteria, including Pasteurellaceae species (Harper and Boyce 2017). In other gram-negative pathogens, LptD has been shown to be an immunogenic target (Zha et al. 2016). Thus, its presence in the shared core genome of the three species examined in this study and the high similarities of its predicted EL domains make it a promising candidate for the treatment of BRD and warrants further study. BamA is a part of the outer membrane protein assembly complex (Albrecht et al. 2014). In other gram-negative pathogens, BamA has been shown to be an immunogenic target (Guan et al. 2016; Luther et al. 2019).

The $0 m p W$ gene identified in this study is present in the core genomes of $\mathrm{H}$. somni, P. multocida, and genotype 2 M. haemolytica, but absent in genotype $1 \mathrm{M}$. haemolytica. Thus, OmpW could be targeted as an intervention strategy against the three Pasteurellaceae pathogens without disturbing the more commensal $M$. haemolytica genotype 1 strains and disrupting the microbial community (Harper and Boyce 2017). The OmpW protein of P. multocida and other gramnegative pathogens has been shown to be immunogenic (Huang et al. 2015; Mohanty et al. 2019).

The OMPs identified in this study may be available for antibody recognition. Within the shared outer membrane core genome of the three Pasteurellaceae species, there are regions of the predicted EL domains that are highly conserved among all three species. This conservation indicates that a host immune response to one or more of the species-wide, conserved OMPs identified in this study could potentially provide cross-immunity to homologous proteins in the other Pasteurellaceae species. This is an area of future investigation. While intra-species cross-protection at the strain or serotype level has been observed for M. haemolytica (Confer and Ayalew 2018) and P. multocida (Rimler 1996), evidence of cross-reactivity between the species is more limited. However, it has been observed between P. multocida and M. haemolytica antigens on outer membrane vesicles in mice (Roier et al. 2013). Additionally, potassium thiocynate extracts of Pasteurella haemolytica have protected mice from challenge with P. multocida (Mukkur 1977), and Haemophilus somnus rabbit immune sera have been shown to agglutinate both $P$. multocida and P. haemolytica (Canto et al. 1983). Of note, H. somnus and P. haemolytica have been reclassified as $H$. somni and $M$. haemolytica, respectively (Angen et al.1999, 2003).

It would be beneficial for the approach used in this study to be applied to deeper populations of $H$. somni and $P$. multocida, as was previously done for $M$. haemolytica. We used bovine-isolated strain genomes available in GenBank for P. multocida and $H$. somni, which probably did not adequately represent the strains populations present in cattle either in the United States or elsewhere throughout the world. It would also be beneficial for future studies to include $H$. somni and P. multocida strains from cattle that did not have or go on to develop BRD. This could potentially provide a level of resolution required to identify OMPs and other genetic determinants that are shared between pathogenic strains and those that have evolved 
into a more constrained commensal biological state. It could also lead to the identification of OMPs that are conserved across some or all three of the Pasteurellaceae species and that associate specifically with $\mathrm{BRD}$ pathogenesis.

\section{Declarations}

\section{Competing interests}

The authors declare that there are no competing interests.

\section{Author contributions}

E.L.W. contributed to project conceptualization, methodology, formal analyses, and writing of the manuscript. M.L.C. contributed to project conceptualization, supervision, reviewing, and editing of the manuscript.

\section{Funding information}

This research was funded by the United States Department of Agriculture (USDA), Agricultural Research Service (ARS) in support of research project 3040-32000-034-00D, "Genomic intervention strategies to prevent and (or) treat respiratory diseases of ruminants"

\section{Data availability}

The authors confirm that all supporting data, code, and protocols have been provided within the article or through supplementary data files and a GitHub link. All sequences used in this study are publicly available in GenBank.

\section{Acknowledgements}

The use of product and company names is necessary to accurately report the methods and results; however, the United States Department of Agriculture (USDA) neither guarantees nor warrants the standard of the products, and the use of names by the USDA implies no approval of the product to the exclusion of others that may also be suitable. The USDA is an equal opportunity provider and employer.

\section{References}

Ackermann, M.R., and Brogden, K.A. 2000. Response of the ruminant respiratory tract to Mannheimia (Pasteurella) haemolytica. Microbes Infect. 2(9): 1079-1088. doi:10.1016/S1286-4579(00) 01262-4. PMID:10967288.

Albrecht, R., Schütz, M., Oberhettinger, P., Faulstich, M., Bermejo, I., Rudel, T., et al. 2014. Structure of BamA, an essential factor in outer membrane protein biogenesis. Acta Crystallogr. D Biol. Crystallogr. 70(Pt. 6): 1779-1789. doi:10.1107/S1399004714007482. PMID:24914988.

Amat, S., Holman, D.B., Timsit, E., Schwinghamer, T., and Alexander, T.W. 2019. Evaluation of the nasopharyngeal microbiota in beef cattle transported to a feedlot, with a focus on lactic acid-producing bacteria. Front. Microbiol. 10: 1988. doi:10.3389/fmicb.2019.01988. PMID:31551953.

Angen, O., Mutters, R., Caugant, D.A., Olsen, J.E., and Bisgaard, M. 1999. Taxonomic relationships of the [Pasteurella] haemolytica complex as evaluated by DNA-DNA hybridizations and $16 \mathrm{~S}$ rRNA sequencing with proposal of Mannheimia haemolytica gen. nov., comb. nov., Mannheimia granulomatis comb. nov., Mannheimia glucosida sp. nov., Mannheimia ruminalis sp. nov. and Mannheimia varigena sp. nov. Int. J. Syst. Bacteriol. 49(Pt. 1): 67-86. doi:10.1099/00207713-49-1-67. PMID:10028248.

Angen, O., Ahrens, P., Kuhnert, P., Christensen, H., and Mutters, R. 2003. Proposal of Histophilus somni gen. nov., sp. nov. for the three species incertae sedis 'Haemophilus sommus', 'Haemophilus agni' and 'Histophilus ovis'. Int. J. Syst. Evol. Microbiol. 53(Pt. 5): 1449-1456. doi:10.1099/ijs.0.02637-0. PMID:13130032.

Berven, F.S., Flikka, K., Jensen, H.B., and Eidhammer, I. 2004. BOMP: a program to predict integral beta-barrel outer membrane proteins encoded within genomes of gram-negative bacteria. Nucleic Acids Res. 32(Web Server issue): W394-W399. doi:10.1093/nar/gkh351. PMID:15215418.

Blom, J., Kreis, J., Spänig, S., Juhre, T., Bertelli, C., Ernst, C., and Goesmann, A. 2016. EDGAR 2.0: an enhanced software platform for comparative gene content analyses. Nucleic Acids Res. 44(W1): W22-W28. doi:10.1093/nar/gkw255. PMID:27098043.

Canto, J., Biberstein, E.L., Schulte, T.A., and Behymer, D. 1983. Cross-reactivity of Haemophilus sommus antibody in agglutination and complement fixation tests and in the enzyme-linked immunosorbent assay. J. Clin. Microbiol. 17(3): 500-506. doi:10. 1128/jcm.17.3.500-506.1983. PMID:6841584.

Caswell, J.L. 2014. Failure of respiratory defenses in the pathogenesis of bacterial pneumonia of cattle. Vet. Pathol. 51(2): 393-409. doi:10.1177/0300985813502821. PMID:24021557.

Clawson, M.L., Murray, R.W., Sweeney, M.T., Apley, M.D., DeDonder, K.D., Capik, S.F., et al. 2016. Genomic signatures of Mannheimia haemolytica that associate with the lungs of cattle with respiratory disease, an integrative conjugative element, and antibiotic resistance genes. BMC Genomics, 17(1): 982. doi:10.1186/s12864-016-3316-8. PMID:27894259.

Clawson, M.L., Schuller, G., Dickey, A.M., Bono, J.L., Murray, R.W., Sweeney, M.T., et al. 2020. Differences between predicted outer membrane proteins of genotype 1 and 2 Mannheimia haemolytica. BMC Microbiol. 20(1): 250. doi:10.1186/s12866-020-01932-2. PMID: 32787780.

Confer, A.W., and Ayalew, S. 2018. Mannheimia haemolytica in bovine respiratory disease: immunogens, potential immunogens, and vaccines. Anim. Health Res. Rev. 19(2): 79-99. doi:10.1017/S1466252318000142. PMID:30683173.

Dabo, S.M., Taylor, J.D., and Confer, A.W. 2007. Pasteurella multocida and bovine respiratory disease. Anim. Health Res. Rev. 8(2): 129-150. doi:10.1017/S1466252307001399. PMID:18218157.

Guan, Q., Wang, X., Wang, X., Teng, D., and Wang, J. 2016. In silico analysis and recombinant expression of BamA protein as a universal vaccine against Escherichia coli in mice. Appl. Microbiol. Biotechnol. 100(11): 5089-5098. doi:10. 1007/s00253-016-7467-y. PMID:27020285.

Harper, M., and Boyce, J.D. 2017. The myriad properties of Pasteurella multocida Lipopolysaccharide. Toxins, 9(8): 254. doi:10.3390/toxins9080254. PMID:28825691.

Hayat, S., Peters, C., Shu, N., Tsirigos, K.D., and Elofsson, A. 2016. Inclusion of dyad-repeat pattern improves topology prediction of transmembrane $\beta$-barrel proteins. Bioinformatics, 32(10): 1571-1573. doi:10.1093/bioinformatics/btw025. PMID:26794316.

Huang, W., Wang, S., Yao, Y., Xia, Y., Yang, X., Long, Q., et al. 2015. OmpW is a potential target for eliciting protective immunity against Acinetobacter baumannii infections. Vaccine, 33: 4479-4485. doi:10.1016/j.vaccine.2015.07.031. PMID:26207591.

Kingsley, R., Rabsch, W., Roberts, M., Reissbrodt, R., and Williams, P.H. 1996. TonB-dependent iron supply in Salmonella by alpha-ketoacids and alpha-hydroxyacids. FEMS Microbiol. Lett. 140(1): 65-70. doi:10.1111/j.1574-6968.1996.tb08316.x. PMID:8666202.

Klima, C.L., Holman, D.B., Ralston, B.J., Stanford, K., Zaheer, R., Alexander, T.W., and McAllister, T.A. 2019. Lower respiratory tract microbiome and resistome of bovine respiratory disease 
mortalities. Microb. Ecol. 78(2): 446-456. doi:10.1007/s00248019-01361-3. PMID:30918994.

Klima, C.L., Holman, D.B., Cook, S.R., Conrad, C.C., Ralston, B.J., Allan, N., et al. 2020. Multidrug resistance in Pasteurellaceae associated with bovine respiratory disease mortalities in North America from 2011 to 2016. Front. Microbiol. 11: 606438. doi:10.3389/fmicb.2020.606438. PMID:33240256.

Luther, A., Urfer, M., Zahn, M., Müller, M., Wang, S.Y., Mondal, M., et al. 2019. Chimeric peptidomimetic antibiotics against gram-negative bacteria. Nature, 576(7787): 452-458. doi:10.1038/s41586-019-1665-6. PMID:31645764.

Mohanty, N., Revanaiah, Y., and Shivachandra, S. 2019. Immunogenicity of recombinant outer membrane protein $(\mathrm{OmpW})$ of Pasteurella multocida serogroup B:2 in mouse model. Ind. J. Anim. Sci. 89.

Mukkur, T.K. 1977. Demonstration of cross-protection between Pasteurella multocida type A and Pasteurella haemolytica, serotype 1. Infect. Immun. 18(3): 583-585. doi:10.1128/iai.18.3.583-585.1977. PMID:591058.

Reissbrodt, R., Erler, W., and Winkelmann, G. 1994. Iron supply of Pasteurella multocida and Pasteurella haemolytica. J. Basic Microbiol. 34(1): 61-63. doi:10.1002/jobm.3620340114. PMID:8207666.

Rice, J.A., Carrasco-Medina, L., Hodgins, D.C., and Shewen, P.E. 2007. Mannheimia haemolytica and bovine respiratory disease. Anim. Health Res. Rev. 8(2): 117-128. doi:10.1017| S1466252307001375. PMID:18218156.

Rimler, R.B. 1996. Passive immune cross-protection in mice produced by rabbit antisera against different serotypes of
Pasteurella multocida. J. Comp. Pathol. 114(4): 347-360. doi:10. 1016/S0021-9975(96)80011-9. PMID:8814530.

Roehrig, S.C., Tran, H.Q., Spehr, V., Gunkel, N., Selzer, P.M., and Ullrich, H.J. 2007. The response of Mannheimia haemolytica to iron limitation: implications for the acquisition of iron in the bovine lung. Vet. Microbiol. 121(3-4): 316-329. doi:10.1016/ j.vetmic.2006.12.013. PMID:17240088.

Roier, S., Fenninger, J.C., Leitner, D.R., Rechberger, G.N., Reidl, J., and Schild, S. 2013. Immunogenicity of Pasteurella multocida and Mannheimia haemolytica outer membrane vesicles. Int. J. Med. Microbiol. 303(5): 247-256. doi:10.1016/j.jimm.2013. 05.001. PMID:23731905.

Singh, K., Ritchey, J.W., and Confer, A.W. 2011. Mannheimia haemolytica: bacterial-host interactions in bovine pneumonia. Vet. Pathol. 48(2): 338-348. doi:10.1177/0300985810377182. PMID: 20685916.

Tanizawa, Y., Fujisawa, T., and Nakamura, Y. 2018. DFAST: a flexible prokaryotic genome annotation pipeline for faster genome publication. Bioinformatics, 34(6): 1037-1039. doi:10. 1093/bioinformatics/btx713. PMID:29106469.

Taylor, J.D., Fulton, R.W., Lehenbauer, T.W., Step, D.L., and Confer, A.W. 2010. The epidemiology of bovine respiratory disease: What is the evidence for predisposing factors? Can. Vet. J. 51(10): 1095-1102. PMID:21197200.

Zha, Z., Li, C., Li, W., Ye, Z., and Pan, J. 2016. LptD is a promising vaccine antigen and potential immunotherapeutic target for protection against Vibrio species infection. Sci. Rep. 6: 38577. doi:10.1038/srep38577. PMID:27922123. 